\title{
Optimization Management System Simulation Teaching by Task-Driven
}

\author{
Chen Yalin ${ }^{1}$, Qiu Xiaofang ${ }^{2}$, Jin Cancan ${ }^{1, *}$, Zhu Yao ${ }^{1}$, He Qifei $^{1}$ \\ ${ }^{1}$ School of Management Science and Engineering, Nanjing University of Finance and Economics \\ ${ }^{2}$ Department of Information Technology, Nanjing Technician College \\ *Corresponding author: Jin Cancan. Email: 123987900@qq.com
}

\begin{abstract}
Management system simulation is one of the professional skills is required for the students majoring in management science. This article analyzes the problems existing in teaching process and introduces task-driven into the course "Management System Simulation" for the better performance. The course has been divided into two modules that are respectively designed according to their characteristics. The article presents the implementation principles and guiding ideology of designing practical tasks considering the background of students. The practical tasks are designed to solve specific problems in management and highlight the application of simulation tools Anylogic, which is multi-phased and multidisciplinary. Moreover, an example of a practical task is demonstrated, which gradually cultivates students' practical ability and independent inquiry ability through implementing the practical task. The teaching process reformed by task-driven discussed in the paper is helpful to improve the teaching effect of the "Management System Simulation" course and draw an improve path for the courses based on multi-disciplines and tool.
\end{abstract}

Keywords: Management System simulation, Task-driven, Teaching reform, Anylogic

\section{COURSE INTTODUCTION AND TEACHING OBJECTIVES}

Management system simulation is one of the professional skills that students majoring in management science should grasp. It provides ideas for finding solutions to management problems efficiently with low cost. As the core course, the management system simulation presents and explains the principles, and then realizing various management system modeling and simulation. Students' abilities of analysis and practice will be improved by the application and research of computer simulation technology in management systems. At present, the course is established in many universities. Theoretical knowledge and skills that are grasped by the students through learning are listed as following:

1) The basic principles, concepts and methods of management system simulation.

2) The ability to establish and analyze quantitative simulation models, design computer simulation programs, and analyze input data and output structures.
3) The ability to use a simulation tool (such as Anylogic) to simulate the management system with computer.

4) The latest technological development and research frontiers in the field of management system simulation.

The listed objectives would be achieved by theoretic knowledge teaching and experiments practice. Since lack of time, the performance is underestimation as we have designed in the training plan. The feedback from the students mentioned that limited case study hasn't worked effectively. We find out the reasons further by questionnaire survey, which shows that the multidisciplines and high requirement for analysis and realization hinder the performance of the students in class time. Then, many students have not been proficient in relevant simulation tools to realize management problem analysis and simulation design until graduation. The taskdriven teaching method is proposed to improve the teaching performance in the limited teaching time. 


\section{THE EXISTING PROBLEMS AND THE NECESSITY OF ADOPTING TASK- DRIVEN TEACHING METHOD}

Given the existing teaching process and performance evaluation, the problems existing in the simulation teaching process of the management system are summarized as follows:

(1) In terms of curriculum setting: in the teaching program of management science majors, the "Management System Simulation" course is offered for juniors. The prerequisite courses include Management Principles, Systems Engineering, Python Programming and Management Information Systems. The students are lack of experience in management problem analysis and program design due to lack of practice although they have completed the basic knowledge accumulation from prerequisite course, which makes it difficult for them to analyze management problems and realize the simulation process in the class.

(2) In terms of teaching content: teaching content of the "Management System Simulation" course is divided into theoretical and application parts. The theoretical part mainly includes behavioral economics and system simulation theory. The application part mainly includes the introduction of simulation tool Anylogic and demonstration of case. Due to the total course hours are less, the cases of management system simulation are less taught in the actual teaching process. Therefore, the students cannot grasp the essence of management system simulation explicitly and fail to master the necessary simulation tool for subsequent professional courses.

(3) In terms of teaching methods and teaching modes: this course teaching is mainly based on teachers' lectures or demonstrations. The simulation experiments which assist in the teaching process are divided into several steps lack of systematic design. Students generally lack enthusiasm and exploratory for learning. It is difficult to realize the systematics simulation for actual management system.

(4) In terms of students' performance assessment: the performance of students is evaluated by the examination which always emphasize on simulation tool or theoretical concept. It's difficult to evaluate the ability of management system analysis by single examination. Therefore, the students who excellent in theoretical assessment, but they are unable to start modeling specific problems.

To solve the problems in the limited class time, we discussed and presented task-driven teaching mode which invite the student join the teaching further and discuss, practice more in their spare time.

\section{THE DESIGN OF PRACTICAL TASKS IN TASK-DRIVEN TEACHING}

\subsection{Principles and concepts of task design}

The task-driven teaching process of the Management System Simulation revolves around a series of practical tasks. Therefore, the design of task-driven teaching is particularly important, and the following principles should be followed:

(1) Phased principle: Before arranging and designing practical tasks, we should make an overall plan for teaching plans and progress, which takes a picture for the different tasks that are classified by problem characters or the difficult levels. According to the plan, the schedule for all tasks is set, as well as the explicit staged target is established for different practical tasks.

(2) Progressive principle: The principle of gradual design from shallow to deep, from module to whole, from basic to application, and from application to innovation should be followed when designing practical tasks. At the same time, we must fully consider the inheritance and gradual nature of the knowledge system involved in practical tasks. Thus, students to consolidate and improve their knowledge and skills in time. Students continuously improve their practical and comprehensive abilities through the implementation of tasks at different levels that are interconnected, mutually promoted, and integrated.

(3) Multidisciplinary integration principle: When designing tasks, we must fully consider the status of management system simulation in the professional curriculum system and the role of discipline tools. It should use Anylogic software to solve specific problems in various disciplines. In addition, students' enthusiasm for learning can be improved by "applying what they have learned to use to promote learning".

According to the above design principles, a task design concept consisting of three layers is formed. The basic layer is a practical task based on the management system simulation clock setting, data calculation and program design. That is arranged in the early stage of teaching activities. The application layer is a practical task based on Anylogic, which is arranged in the middle of the teaching activity. In this layer, it uses a single simulation method to simulate simple problems in the management system. The innovation layer is the sublimation stage of task-driven teaching arranged at the end of teaching. In this stage, we design and integrate a variety of simulation methods to abstract and realistic management problems. Those problems are realized by students' self-organized teams to sublimate the theoretical and practical skills learned. And then the students' comprehensive application ability and innovation ability are improved. 


\subsection{Practical process and cases of management system simulation practical tasks}

The practical tasks of management system simulation must give full play to and reflect the initiative and dominant position of students. We have to inspire students to use Anylogic software to analyze and solve management problems, and cultivate students' ability of collaboration, exploration and innovation in the process. The specific process is as follows:

Step1: Task scheduling. Students are required to collaborate with each other in a group of 5 people to analyze, design and simulate a specific management problem.

Step2: The team builds a system simulation model in the Anylogic environment, including problem structure, initialization parameters, and setting requirements.

Step3: Based on the dynamic data set and experimental functions, the team designs a variety of simulation experiments and conducts comparative analysis.

Step4: Perform a demonstration based on the above content and analyze the process improvement and program evaluation results based on the simulation results.

Driven by practical tasks, team members complete basic tasks through discussion and collaboration. We make a specific task to demonstrate the process of taskdriving teaching.

This task is arranged at mid-term after learning the theoretic concept as the beginning of simulation. The problem is about the diffusion of new product. It is known that a company sells a new product in a market of a certain scale. Consumers are sensitive to advertising and word-of-mouth. The product life cycle is unlimited, and there is no repeated purchase. Students are required to build a basic model in the Anylogic environment, complete the comparison of plans under the number of contacts and the impact of advertising efficiency on the conversion process. The process of new product diffusion is simulated by system dynamics in the Anylogic environment, as shown in Figure 1:

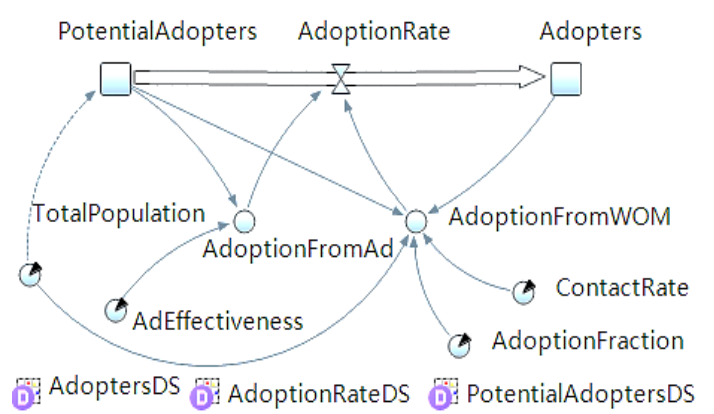

Figure 1. New product diffusion process simulation
From the figure 1, the students explain the process for establishing flow-chart. To further research, the comparative experiment and sensitivity analysis are shown in Figure 2 and Figure 3 respectively:

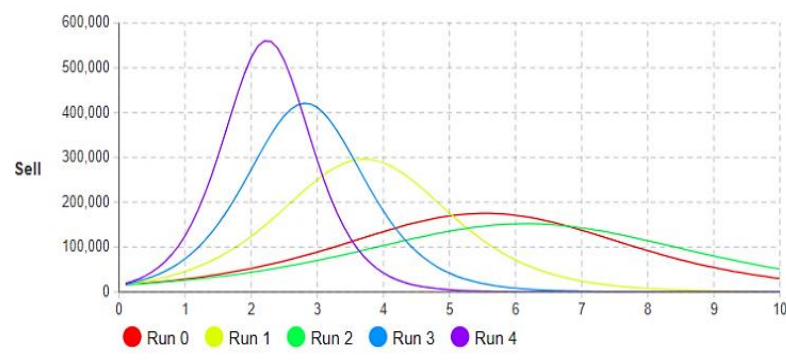

Figure 2. Changes in the diffusion process of new products under different numbers of contacts

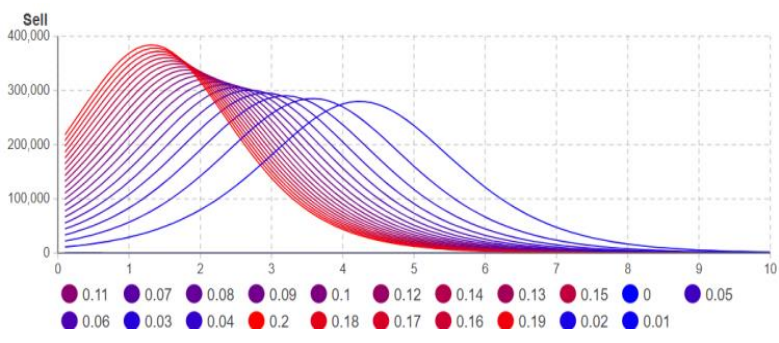

Figure 3. The effect of advertising efficiency on the diffusion process of new products

It can be seen from figure 2 that an increasing number of contacts will increase word-of-mouth sales and accelerate the increase in sales. From the figure 3, when the advertising efficiency is reduced from 0.11 to 0.01 , the diffusion process of new products tends to be flat, and sales growth slows.

The example introduced is one of tasks in series. The students complete this task and develop the more complex one under different situation. The feedback from students is mainly positive and inspiring.

\subsection{Task assessment and evaluation}

After the task is completed, each group will select a student representative to summarize the implementation process and results of the practical task. In the task implementation process, each team can make appropriate expansions on the basis of the original task according to their actual situation. Finally, they ought to fill in the task report with the implementation plan, operation results, expanded functions and performance analysis of the practical task.

The achievement of the practical task=implementation plan $\times 30 \%+$ operation result $\times 30 \%+$ extended function $\times 20 \%+$ performance analysis $\times 20 \%$. Task-driven teaching and assessment can cultivate students' practical ability, innovation ability and teamwork spirit. It can also improve students' initiative and enthusiasm in learning. Meanwhile, the 
teaching effect of "Management System Simulation" has been generally improved

\section{CONCLUSION}

In the teaching reform of "Management System Simulation" course, practical tasks are interspersed in the actual teaching process. According to the characteristics of different modules of the course, we interspersed practical tasks in the actual teaching process. The practical tasks are designed to be phased, progressive, and multidisciplinary. It can solve specific problems in management and highlight the application of Anylogic simulation tools. In this paper, we analyze and summarize the principles and guiding ideology for management practical tasks design. Moreover, a teaching example of practical task demonstrate the implementation of process. The task implementation can guide the teaching process, which gradually develop students' practical ability and independent inquiry ability. Task-driven teaching process is helpful to improve the performance by inspiring the students. The teaching method make a valued suggestion for the similar courses that are under multi-disciplines and limited class time.

\section{ACKNOWLEDGMENTS}

The paper is supported by Ministry of Education Humanities and Social Sciences Youth Project "coal related industrial policy under water resources constraints: mechanism, model and simulation" (No. 18yjczh016) \& Nanjing University of Finance and Economics Schoollevel Teaching Reform Project (No. JGY19071)

\section{REFERENCES}

[1] Wang Wanjun, Chen Wei. Teaching research and exploration of management system simulation course [J]. Education and Teaching Forum, 2015 (20): 152-153.

[2] Zheng Xiaoxue, Lin Wei. Practice and Discussion on application oriented Undergraduate Teaching of analogic [J]. Journal of higher education, 2018 (7): 67-70.

[3] Li Xiuying, Wang Jianxin, Peng Jing. Application of task driven teaching method in anylogic teaching [J]. Journal of electrical and electronic teaching, 2010 , 32( 2) : 104-105 .

[4] Weng Guoqing, Qi Jun, Xie Luyao. Multi direction integrated classroom teaching reform based on task driven -- Taking "analogic and system simulation" course as an example [J].Journal of Higher Education , 2019( 1) : 82-84.

[5] Hoedelmoser S., Kitzler F. Comparison of MATLAB, Simulink and Anylogic Approach to ARGESIM Benchmark C9 'Fuzzy Control of a Two Tank System'[J]. SNE Simulation Notes Europe, 2013, 23(3-4)

[6] Assimakopoulos N., Theocharopoulos I. The Design and Control Systemic Methodology (DCSYM): a multi-agent modelling and operation platform[J]. International Journal of Applied Systemic Studies, 2009, 2(3):193.

[7] He C, Luo Y, Liu G . Teaching Cases Analysis of Integration of Electromechanical Control of Linkage Mechanism[J]. Journal of Physics: Conference Series, 2021, 1735(1): 012013 (5pp).

[8] Srećko Stamenković, Nenad Jovanović, Chakraborty P. Evaluation of simulation systems suitable for teaching compiler construction courses[J]. Computer Applications in Engineering Education, 2020(3).

[9] Zhao, Y. (2020). Research and development of economic crisis data simulation teaching analysis system based on fractional calculus equation. Chaos Solitons \& Fractals, 130, 109460.

[10] Chulkov, D., \& Wang, X. (2020). The educational value of simulation as a teaching strategy in a finance course. e-Journal of Business Education and Scholarship Teaching, 14. 